\title{
Innovative heat pipes and thermosyphons for renewable sources of energy application
}

\author{
Leonard Vasiliev, ${ }^{1, *}$, and Alexander Zhuravlyov ${ }^{1}$ \\ ${ }^{1}$ Luikov Heat and Mass Transfer Institute of the NAS of Belarus, Porous Media Laboratory, 15 P. Brovka str., 220072, Minsk, Belarus
}

\begin{abstract}
In the paper the authors present possibilities of use two-phase heat-conducting devices at cooling technologies for PV and PV/T solar cooling and air-conditioning. Three ways to improve heat conductive properties of heat pipes and thermosyphons with help of nanotechnologies are considered: use of nanofluids, application of nanocoatings on heat loaded surfaces and polymer composites with nanoparticles producing. A mini bubbles generation of the working fluid inside the transparent thermosyphon evaporator with nanocoating under the solar radiation influence was observed. Nanotechnologies allow to intensify heat transfer processes and reduce energy losses in original designs of heat pipes and thermosyphons.
\end{abstract}

\section{Introduction}

Issues in sustainable development and climate change are directly related to problems of heat and mass transfer. The field of heat and mass transfer holds some of the key phenomena of human activities and in many branches of industry: chemical, energy conversion and power generation, food-processing and pharmaceutics, material processing and metallurgy, transportation and space technology, electronics cooling, bioengineering and biomedical applications, indoor climate, and the care for the environment. Despite decades of development, the science and engineering of heat and mass transfer are continuously being confronted with new challenges in search of new and improved technologies. Some of the multiple facets of heat and mass transfer are still awaiting proper understanding and continue to be in worldwide research focus. Developments in computer simulations in synergy with sophisticated experimental and diagnostics techniques open new frontiers for discoveries and innovation in both conventional and emerging technologies. Recently, we have witnessed expansion of scales into micro and nanoscales, where some very new technologies are in the offing, and into mega- and giga-scales encountered in the atmosphere, oceans, interior of the Earth, and outer space. The need to collect and store solar energy has broadly resulted in two solar energy conversion methods being developed. The first one is photovoltaic and involves converting solar energy directly into electrical energy. The second is solar thermal and involves converting solar energy directly into thermal energy, or cold. Nanofluids, nanocoatings and nanocomposites inventions open a new niche in the heat pipe and thermosyphon design and use for solar energy application. The combination of nanofluid and small channels constitutes an innovating method providing effectiveness, compactness and low thermal resistance of heat pipes. In certain applications polymers composites reinforced by carbon nanowires and nanoparticles can successfully replace the metal envelope of heat pipes and thermosyphons.

The topic of this presentation is related to the field of cooling technologies for PV and PV/T solar cooling and air-conditioning. Solar energy is one of the most interesting solutions among renewable energy resources as it can be converted easily whether into heat, cold, or into electricity. The main problem when using such an energy source is its unfair time distribution which may cause mismatch between needs and availability. Long thermosyphons (vapordynamic thermosyphons, VDT, and flat polymeric loop thermosyphons, FPLT) are of great interest as components of heat exchangers for recuperation of energy of renewable sources (solar, ground) and upgrading their potential with the help of heat pumps. Transparent thermosyphons with nanofluids and nanocoated surface inside presented in this research program are a good tool to absorb solar radiation in the volume of the fluid flow. Vapordynamic thermosyphons cooling system is good solution for building-integrated photovoltaic technology. Development of the new environmentally - friendly and energy - efficient technologies will be vital to achieving investigation of a hybrid PHOTOVOLTAICS/THERMOCOLLECTOR $(\mathrm{PV} / \mathrm{T})$ systems, providing electricity and heat/cold simultaneously, represents an important step toward reducing dependency on fossil fuels.

Colloidal suspensions of nanosized particles in a fluid, have recently gained popularity as cooling fluids mainly due to their enhanced heat transfer capabilities [1].

Actually the micro and nanoparticles (NP) as nanocoating (NC) of the heat pipe evaporators and thermosyphons are suggested as means to increase the heat transfer coefficient with working fluid evaporation

Corresponding author: Leonard.L.Vasiliev@gmail.com 
and boiling on the heat loaded wall [2]. When NPs are properly dispersed, NFs can offer numerous benefits besides the anomalously high effective thermal conductivity, such as improved heat transfer and stability, microchannel cooling without clogging, the possibility of miniaturizing systems scaling, or reduction in pumping power, among others. NCs of the heat pipe evaporators and NPs based polymer composites design are considered as a mean to increase its effective thermal conductivity. The generation of engineered nanostructures represents a major breakthrough in material science and nanotechnology.

\section{Nanofluids for heat pipes}

In some cases it is interesting to make the minichannels heat exchanger and heat pipes envelope from transparent material (glass, plastic) and to heat the working fluid in volume by solar, or laser radiation, Fig. 1.

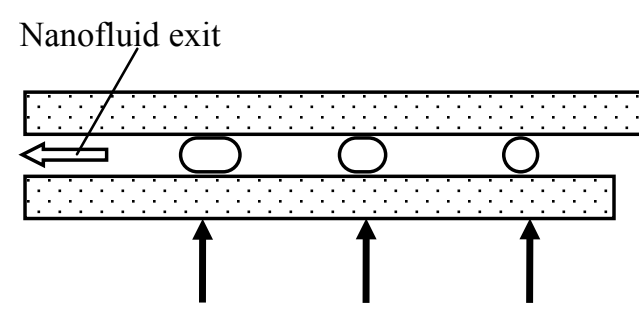

Laser beams to heat the nanofluid

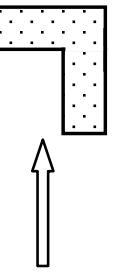

Nanofluid entrance
Fig. 1. Schematic of the flat minievaporator with transparent walls heated by impulse laser beam.

Bubbles generation phenomena in minivolumes filled with nanofluid due to the laser beam interaction with solid particles is the reason of NFs circulation in the mini heat pipe loop, or thermosyphon. This impulse is working as two-phase minipump, which initiate the fluid circulation inside minichannel, Fig. 2.
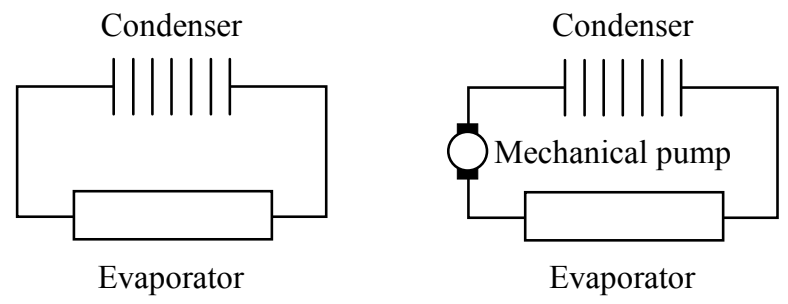

Fig. 2. Schematic of two-phase loop thermosyphon with nanofluid circulation (without mechanical pump - left, and with mechanical pump - right).

Bubbles are considered also as a motive force to organize the fluid circulation in pulsating heat pipes and loop thermosyphons. One of the major interesting topics is the investigation of the influence of metal oxide NPs $\left(\mathrm{CuO}, \mathrm{Al}_{2} \mathrm{O}_{3}\right.$ nanoparticles) immersed in the fluid (water) on the local bubbles generation and two-phase heat transfer intensification to compare with pure water.
It was shown $[3,4]$ that the heat flow generated by lightabsorbing nanoparticles (gold, or $\mathrm{Cu}$ NPs) initiates more intense bubble generation. Transparent evaporators made from glass or plastic have a real practical interest for solar energy application (Figs. 3, 4). So, application of plasmonic nanofluids in photothermal use, for example in solar thermal receivers, is a strong subject of interest in current research.

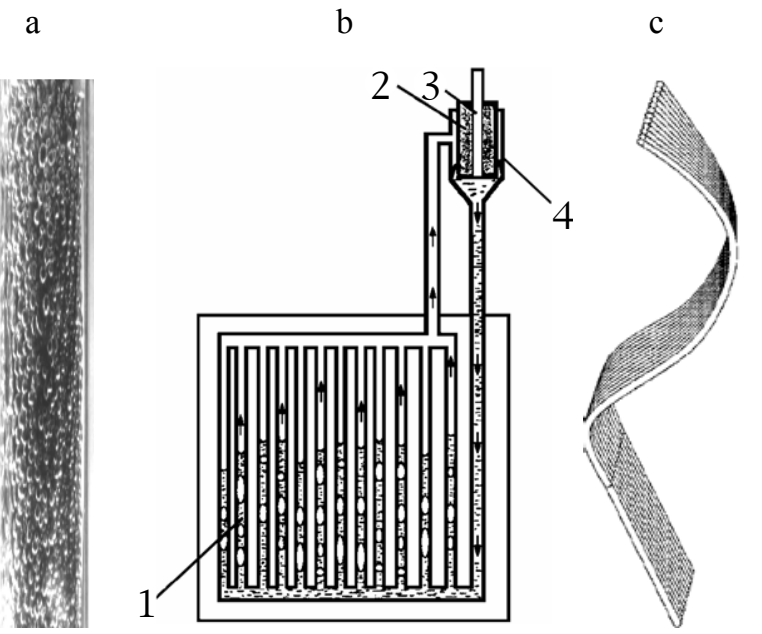

Fig. 3. Bubble generation in the evaporators of heat pipes and thermosyphons under solar radiation: a) nanofluid $\left(\mathrm{Al}_{2} \mathrm{O}_{3}\right)$ absorbing solar radiation inside the transparent (glass) pipe; b) transparent pulsating heat pipes: 1 - multi evaporators, 2 - heat exchanger, 3 - cooler, 4 - condenser; c) polymeric transparent pulsating heat pipe [5].

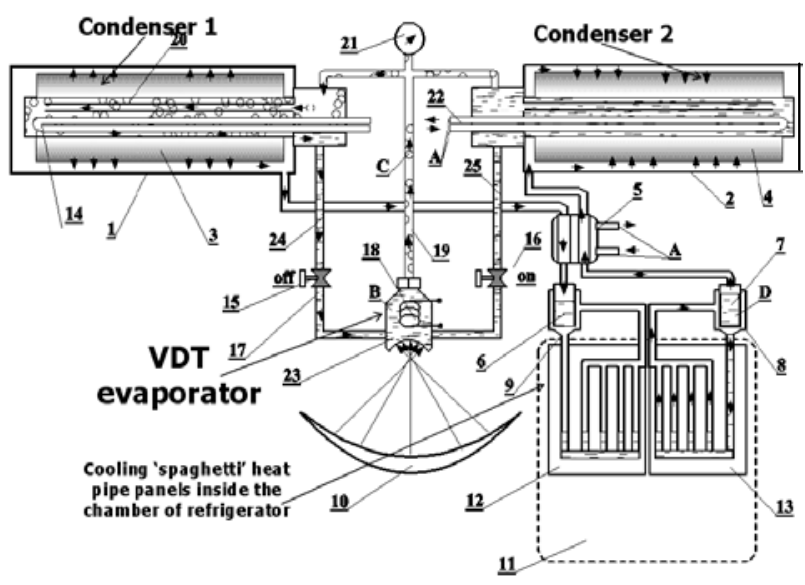

Fig. 4. VDT with two condensers as a cooler/heater for solar solid sorption refrigerator (nanofluid inside the evaporator) [4]: 1, 2 - adsorbers, 3, 4 - sorbent beds, 5 - liquid heat exchanger, 6,7 - ammonia accumulators, 8,9 - "spaghetti" heat pipe condensers, 10 - parabolic solar concentrator, 11 - refrigerator chamber, 12 - "freezer", 13 - "spaghetti" evaporators , 14, 22 cooling liquid heat exchanger, 15,16 - valves, 17 - VDT liquid pipe, 18 - electric heater, 19 - VDT vapor pipe, 20 adsorber vapor channels, 21 - pressure sensor, 23 - VDT evaporator (solar absorber), A - cooling liquid heat exchanger, $\mathrm{B}$ - VDT evaporator envelope, C - two phase flow of the working fluid, $\mathrm{D}-$ ammoniac low-temperature circuit. 


\section{Nanocoatings in heat pipes}

In photovoltaic (PV) systems, incoming sunlight strikes a semiconductor material (crystalline silicon) and dislodges electrons in the material to cause the movement of electrons. The resulting electron flow generates the PV cells electrical output. However, only a small portion of incident solar energy (typically less than $20 \%$ ) is transformed into electrical energy. The remaining incident energy increases the temperature of the PV cell and reduces its operational performance, Fig. 5.

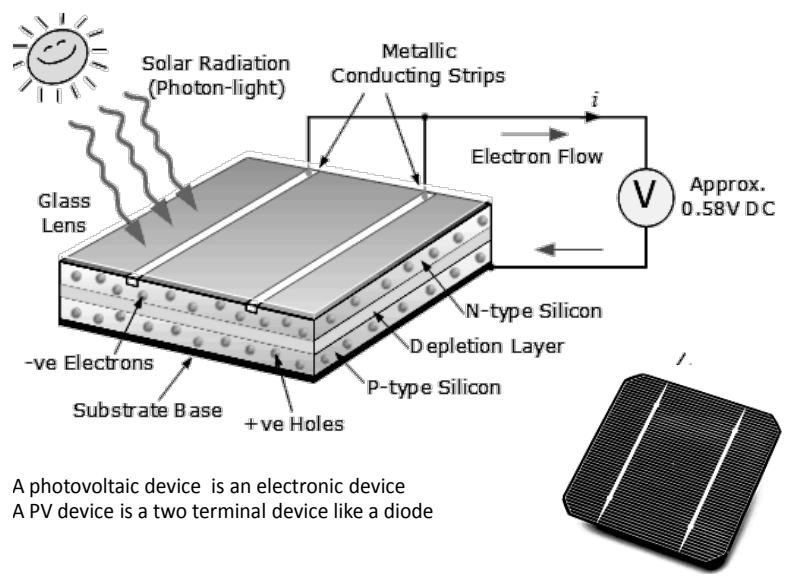

Fig. 5. Photovoltaic solar cells application efficiency depends on the silicon film temperature.

Good means to improve solar cells efficiency of electricity production is to cool solar cell near the ambient temperature using heat pipe heat exchanger (VDTs with long horizontal evaporator and condenser).

If the thermosyphon, or heat pipe envelope is made from the transparent material (glass), there is a possibility to organize the volumetric absorption of solar radiation inside the evaporator. Inside the annular evaporator of thermosyphon there is a metallic tubular solar receiver coated by nanoparticles such as $\mathrm{CuO}$, or $\mathrm{Al}_{2} \mathrm{O}_{3}$ (Fig. 6). This receiver is partly immersed to the working fluid (water, propane). The temperature profile inside such thermosyphon is different to compare with conventional thermosyphon (Fig. 7).

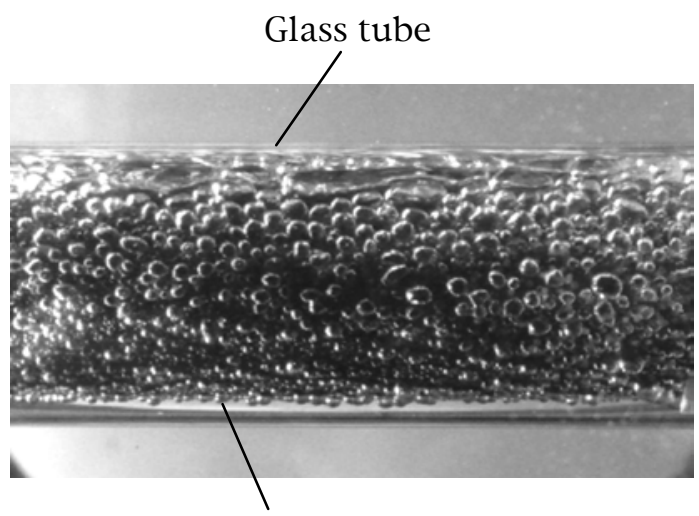

Minibubbles generation

Fig. 6. Mini bubbles generation of the working fluid inside the transparent thermosyphon evaporator with nanocoating under the solar radiation influence. Working fluid - propane.

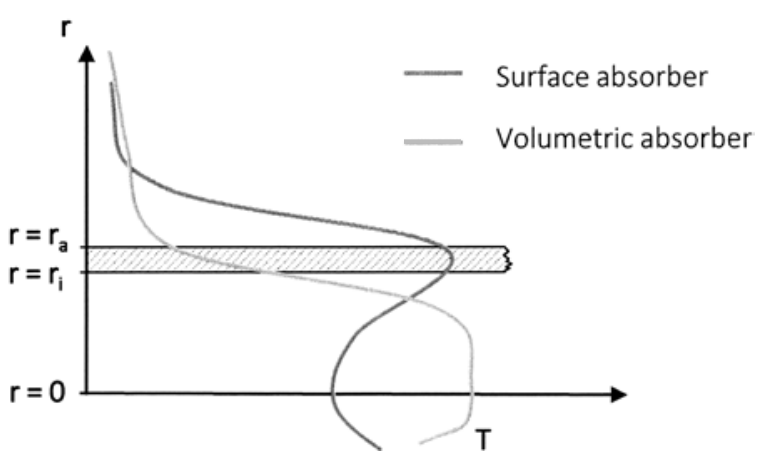

Fig. 7. Temperature field evolution (cross section) in copper tube solar thermal absorber with water (surface solar absorption), and transparent glass solar absorber with nanofluid (water $+\mathrm{CuO}$ nanoparticles; volumetric absorption of solar radiation) [6].

The copper loop thermosyphon has a thin and long horizontal evaporator (length $200 \mathrm{~mm}$, diameter $10 \mathrm{~mm}$ ) and liquid cooled cylindrical condenser [7], (Fig. 8). Miniature copper sintered powder porous coating less $1 \mathrm{~mm}$ thick is put inside the evaporator. Thermosyphon is made self-priming by carefully controlling condenser, vapor line and liquid line and the volume of the compensation chamber. The compensation chamber and fluid charge are set so that there is always fluid in the compensation chamber even if the condenser, vapor line and liquid line are completely filled with the liquid. Thermosyphon condenser is cooled by the liquid (water) from the cooling bath flowing through the annular liquid heat exchanger. The low temperature cooling liquid flow is maintained via a thermostat with its flow rate being measured by a flow meter. The temperature of the cooling liquid is regulated from 20 up to $80^{\circ} \mathrm{C}$ to give a possibility to change the temperature of the vapor condensation inside thermosyphon.

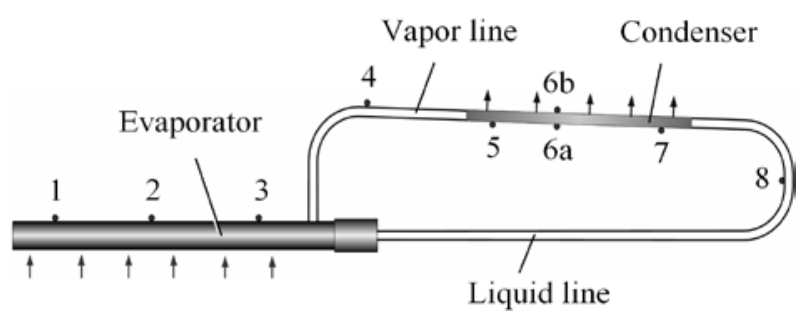

Fig. 8. Loop thermosyphon with cylindrical horizontally disposed evaporator and condenser; 1-8 are the thermocouples position on the thermosyphon surface.

The pressure drop during a working fluid circulation inside thermosyphon is calculated as

$$
\Delta P_{\text {cap }}+\Delta P_{\mathrm{g}}+\Delta P_{\text {bg }} \geq \Delta P_{\mathrm{L}}+\Delta P_{\mathrm{v}}+\Delta P_{\mathrm{e}}+\Delta P_{\mathrm{c}}
$$

The notations $\Delta P_{\text {cap }}$ is the capillary pressure of the wick; $\Delta P_{\mathrm{g}}$ is the gravitational pressure loss; $\Delta P_{\mathrm{bg}}$ is the bubble generation pressure drop in the evaporator; $\Delta P_{\mathrm{L}}$ is the pressure drop of the liquid flow; $\Delta P_{\mathrm{v}}$ is the pressure drop of the vapor flow; and $\Delta P_{\mathrm{e}}$ and $\Delta P_{\mathrm{c}}$ are the preassure drop due to evaporation and condensation at the liquid-vapour interface respectively. 
For the thermosyphon to function properly, the $\Delta P_{\text {cap }}+$ $+\Delta P_{\mathrm{g}}+\Delta P_{\mathrm{bg}}$ ought to be larger or at least equal to the sum of all the pressure losses mentioned above. To increase the capillary pressure and permeability of the wick, the wick ought to have a heterogeneous porous structure (micro, mesa and macro pores). The wick will require a high liquid surface tension $\sigma$, low contact angle $\theta$ (i.e. high liquid wettability) and small powder size for low effective pore size radius $R_{\text {eff }}$.

The average temperature difference between the evaporator and condenser, $\Delta T_{\mathrm{avg}}$, is found by subtracting the average, front-end condenser temperature, $T_{\mathrm{c}}$, from average front-end evaporator temperature, $T_{\mathrm{e}}$. Both the evaporator and condenser temperatures were found using Eqs. (2), (3):

$$
\begin{aligned}
& T_{\mathrm{e}}=\frac{T_{1}+T_{2}+T_{3}}{3}, \\
& T_{\tilde{\mathrm{n}}}=\frac{T_{5}+T_{6}+T_{7}}{3},
\end{aligned}
$$

where $T_{1}, T_{2}, T_{3}$ and $T_{5}, T_{6}, T_{7}$ are the temperatures occurring at the respective thermocouples locations on the evaporator and condenser; $T_{4}$ and $T_{8}$ are the temperatures occurring at the respective thermocouples locations on the vapor and liquid lines of thermosyphon (Fig. 8). The cooling capacity of LTCE condenser is calculated from the following expression:

$$
Q_{\text {out }}=m \cdot c_{p}\left(T_{\text {out }}-T_{\text {in }}\right),
$$

where $m, c_{p}, T_{\text {out }}$ and $T_{\text {in }}$ represent the flow rate, specific heat at the constant pressure, outlet temperature and inlet temperature of chilled water, respectively.

$$
R_{\text {total }}=\Delta T / Q=\left(T_{\mathrm{e}}-T_{\mathrm{c}}\right) / Q_{\text {actual }},
$$

where $T_{\mathrm{e}}$ and $T_{\mathrm{c}}$ are the average temperature of the evaporator and condenser; $Q_{\text {actual }}$ is representing the average of the heat removal form of the condenser and supplied input power $\left(Q_{\text {input }}=(I \times V)\right.$. The dimensions of thermosyphon charged with water are shown on the Table 1. The temperature of components and thermal resistance of thermosyphon via time and heat input is presented in Fig. 9 and in the Table 2.

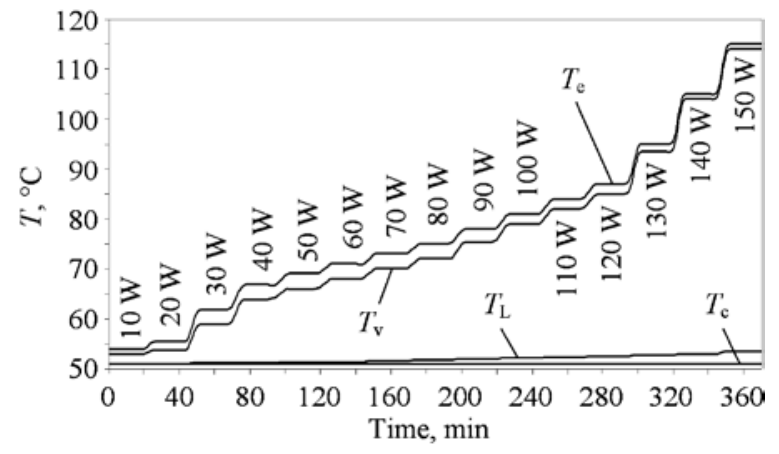

Fig. 9. Temperature of thermosyphon components via the time for different heat loads. Working fluid is water. $T_{\mathrm{e}}, T_{\mathrm{v}}, T_{\mathrm{c}}$ and $T_{\mathrm{L}}$ are the temperatures of evaporator, vapor, condenser and the working liquid of thermosyphon respectively.
The working fluid at the entrance of the evaporator is subcooled and its temperature is close to the temperature ( $\left.T_{\text {sink }}\right)$ of the liquid inside the cooling bath.

Table 1. Dimensions of the thermosyphon, $\mathrm{mm}$.

\begin{tabular}{|c|c|c|c|}
\hline $\begin{array}{c}\text { Heat load } \\
\text { (W) }\end{array}$ & $R_{\mathrm{t}}(\mathrm{K} / \mathrm{W})$ & $R_{\mathrm{e}}(\mathrm{K} / \mathrm{W})$ & $R_{\mathrm{c}}(\mathrm{K} / \mathrm{W})$ \\
\hline 10 & 0.3 & 0.1 & 0.2 \\
\hline 20 & 0.22 & 0.085 & 0.135 \\
\hline 30 & 0.36 & 0.1 & 0.26 \\
\hline 40 & 0.39 & 0.075 & 0.32 \\
\hline 50 & 0.35 & 0.06 & 0.29 \\
\hline 60 & 0.32 & 0.05 & 0.27 \\
\hline 70 & 0.3 & 0.043 & 0.26 \\
\hline 80 & 0.3 & 0.029 & 0.26 \\
\hline 90 & 0.28 & 0.027 & 0.26 \\
\hline 100 & 0.29 & 0.01 & 0.28 \\
\hline 110 & 0.29 & 0.01 & 0.28 \\
\hline 120 & 0.29 & 0.008 & 0.28 \\
\hline 130 & 0.4 & 0.015 & 0.38 \\
\hline 140 & 0.4 & 0.007 & 0.4 \\
\hline 150 & 0.4 & 0.007 & 0.4 \\
\hline
\end{tabular}

\begin{tabular}{|l|c|}
\hline \multicolumn{1}{|c|}{ Dimension } & mm \\
\hline Length of the evaporator & 200 \\
\hline Diameter/wall thickness of the evaporator & $12 / 1$ \\
\hline Length of the condenser & 460 \\
\hline Diameter/wall thickness of the condenser & $4 / 0.5$ \\
\hline Length of the vapor line & 300 \\
\hline Diameter/wall thickness of the vapor line & $4 / 0.5$ \\
\hline Length of the liquid line & 220 \\
\hline
\end{tabular}

Table 2. Thermal resistance $R$ of the evaporator, condenser and total of thermosyphon $\left(T_{\text {sink }}=50^{\circ} \mathrm{C}\right)$.

Thermosyphon action was checked both with multiple increasing and decreasing of the heat load. Good performance characteristics of the copper-water LTCE are also confirmed by the almost complete absence of hysteresis phenomena (Fig. 10). The solid lines indicate the evaporator heat flux is increasing; the dotted lines indicate a decrease in the heat load. 


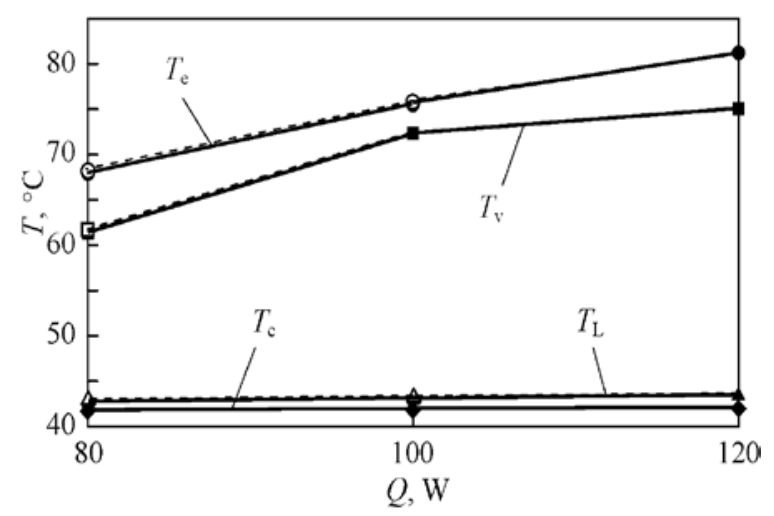

Fig. 10. Temperatures of thermosyphon via heat load $Q$ with water as a working fluid: $T_{\mathrm{e}}, T_{\mathrm{v}}, T_{\mathrm{c}}$ and $T_{\mathrm{L}}$ are the temperatures of evaporator, vapor, condenser and working fluid (near the evaporator).

The solar PV collectors with thermosyphon coolers are shown on Fig. 11. They are cooled by the air (natural convection), or by the liquid forced convection. Evaporators of thermosyphons are inserted into the basement of the solar collector; finned condensers are installed on the back side of collector and are cooled by the natural convection of the air, or heat exchanger with water circulation

a

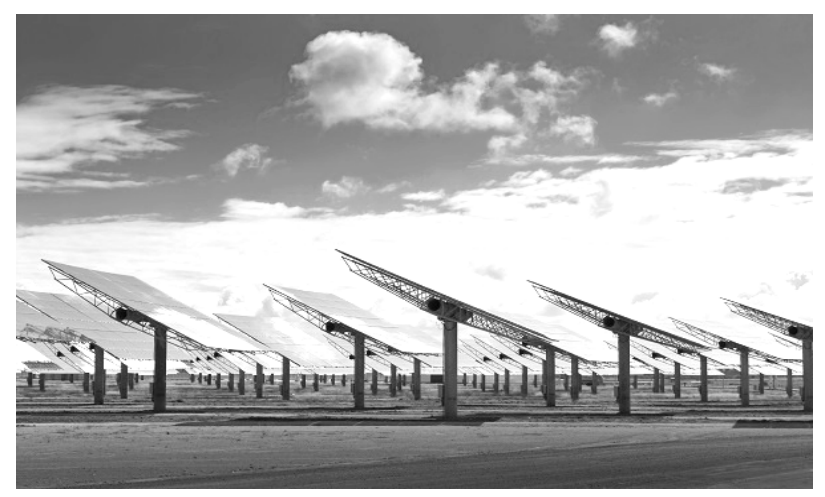

b

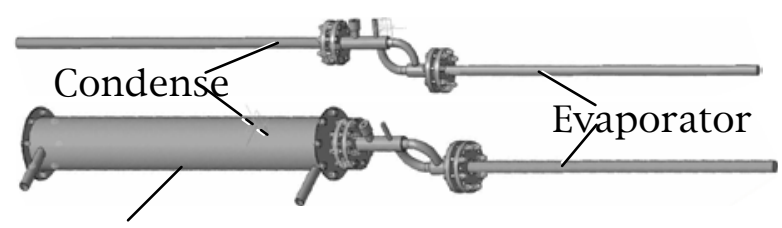

Heat exchanger

Fig. 11. Solar collectors (a) and VDT thermosyphons as its cooling components (b).

The VDT is less sensitive to the angle of its inclination (Fig. 12) to compare with conventional thermosyphon. VDT has low thermal resistance $R=0.22 \mathrm{~K} \cdot \mathrm{W}^{-1}$. The conventional thermosyphon has its thermal resistance $R=0.25-0.3 \mathrm{~K} \cdot \mathrm{W}^{-1}$ for the near horizontal position of the evaporator, and $R>0.5 \mathrm{~K} \cdot \mathrm{W}^{-1}$ for its negative inclination to horizon. The heat flow $Q=100 \mathrm{~W}$ transferred by VDT is near 1.7 time more to compare with conventional thermosyphon $Q=60 \mathrm{~W}$ at the same mean temperature of the condenser.

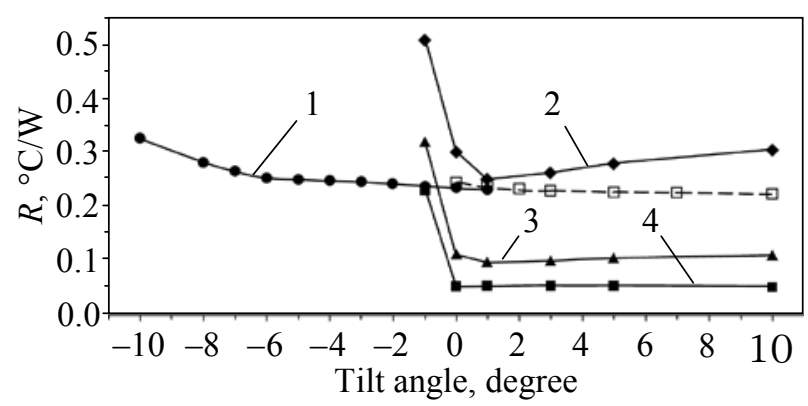

Fig. 12. Thermal resistance of VDT thermosyphon ( 1 - total $)$ and conventional thermosyphon (2 - total, 3 - condenser, $4-$ evaporator) as a function of the angle of thermosyphon inclination.

\section{Polymer composites with nano- particles}

Recently a new nanotechnology was developed to produce loop polymer thermosyphons capable of longterm operation without permeation by air or working fluids through their walls [8]. Polymer-metal composites are becoming an attractive subject due to their unique surface morphology. Nanocoating of the heat loaded surface of such polymer have a grand potential to increase the wettability and heat transfer intensity in small size heat transfer devices. Actually polymer heat transfer equipment is used in different devices. The application of horizontal flat polymer thermosyphons to apply the energy of alternative energy sources (solar and ground sources of energy generation), cooling and heating of the buildings and storehouses has a good future. Thermosyphon (Fig. 13) has a flat interface (for attaching heat-generating elements) and flexible transport lines (vapor and liquid pipes) between the flat evaporator and condenser. The working fluid of thermosyphon is isobutene ( $\mathrm{R} \mathrm{600).}$

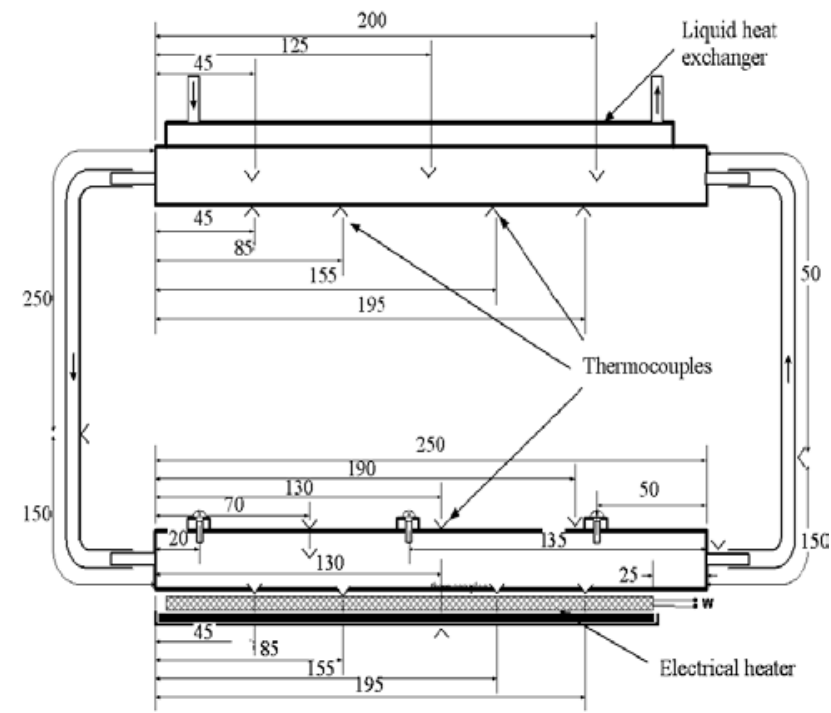

Fig. 13. Flat loop thermosyphon made from polymer composite (Polyamide reinforced by carbon nanofilaments and nano diamond particles). 
The distance between the evaporator and condenser can constitute several meters. This thermosyphon operates autonomously under the action of the gravity forces and under the temperature drop between the heat source and heat sink. There are some rectangular minigrooves as a capillary structure inside the evaporator and condenser of the thermosyphon.

The envelope of thermosyphon is made of polyamide composite with nano carbon filaments and nano diamond particles to increase its effective thermal conductivity. The effective thermal conductivity of composite is equal to $11 \mathrm{~W} /\left(\mathrm{m} \cdot{ }^{\circ} \mathrm{C}\right)$.

The width and length of thermosyphon is 50 and $250 \mathrm{~mm}$, respectively. The width of the grooved surface inside the evaporator and condenser, where two-phase heat transfer occurs is $30 \mathrm{~mm}$. The width and depth of the rectangular minigrooves inside the evaporator and condenser are $2.5 \mathrm{~mm}$. The thickness of the evaporator and condenser is $10 \mathrm{~mm}$. The width and thickness of the rectangular parts of frames are $10 \mathrm{~mm}$, respectively.

The difference between the temperature of the external walls of the evaporator $T_{\mathrm{w}}$ and the saturated temperature of the adiabatic (vapor transport) zone $T_{\text {sat }}$, i. e., $T_{\mathrm{w}}-T_{\text {sat }}$, was measured directly by four thermocouples, one junction of which was on the evaporator wall, while the other was placed in a thermally controlled liquid bath. The vapor saturation inside the thermosyphon was maintained using the liquid heat exchanger and thermostat. The total thermal resistance of the thermosyphon $R_{\mathrm{TS}}$ was calculated as

$$
R_{\mathrm{TS}}=\frac{T_{\mathrm{e}}-T_{\mathrm{c}}}{Q}
$$

where $T_{\mathrm{e}}$ is the mean temperature of the evaporator $\left({ }^{\circ} \mathrm{C}\right)$, $T_{\mathrm{c}}$ is the mean temperature of the condenser $\left({ }^{\circ} \mathrm{C}\right)$, and $Q$ is the heat flow (W).

The experimental technique was used to perform some necessary operations including temperature measurements (Agilent Data Acquisition Agilent Data Loger HP-34970A with a set of thermocouples connected to the computer), measurements of the heat flow $Q$ from the evaporator to condenser and of the effective thermal conductivity of the thermosyphon envelope. To cool the thermosyphon condenser (liquid loop) a Joulabo F12 recirculation thermal bath with temperature-regulated accuracy of $\pm 0.5{ }^{\circ} \mathrm{C}$ was used. The heat flow was supplied by an electric cartridge heater located on the bottom surface of the evaporator. The heat sink (liquid heat exchanger) was attached to the top of the condenser. All measurements were performed in a steady-state regime for the heat flow range of 50$100 \mathrm{~W}$.

The temperature distribution along the evaporator, transport zone, and condenser as a function of the heat load is shown in Fig. 14.

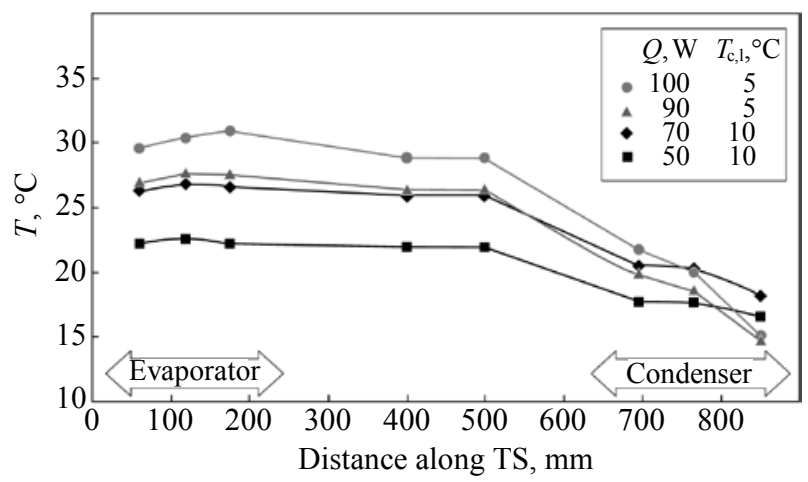

Fig. 14. Temperature distribution along the evaporator, transport zone and condenser of the thermosyphon as the function of heat input.

\section{Conclusion}

Recent advances in nanotechnology have allowed development of a new nanofluids, nanocoatings and nano polymer composites intensifying heat transfer processes and reducing energy losses in original designs of heat pipes and thermosyphons. Application of photo thermal microscopy allows visualizing individual bubbles generation in transparent mini-evaporator. Visualization of the hydrodynamic and heat transfer of two-phase flow in horizontal annular mini-channel allows analyzing the efficiency of porous coating influence on hydrodynamic and heat transfer in minichannels and thermosyphon evaporators. Nanofluids and nanocoatings may be recommended in solar thermal applications due to very effective volumetric absorption and good solar radiation properties.

\section{References}

1. S. Kakaç, A. G. Yazicioglu. CONV-14, Int. Symp. Convect. Heat Mass Transf., 1 (2014).

2. F.P. Cabral, G. Ribatski. ENCIT 2010 - 13th Braz. Congr. Thermal Sci. and Eng. (2010).

3. D. Lapotko, E. Lukianova. Int. J. Heat Mass Trans. 48, 227 (2005).

4. L. Vasiliev, D. Lapotko, E. Lukianova, A. Zhuravlyov, A. Shapovalov, L. Vasiliev Jr. 14th IHPC - 14th Int. Heat Pipes Conf. 138 (2007).

5. L. Vasiliev Jr. Heat exchange device made of polymeric material. Pat. US 2011/0067843 A1. 2011.

6. J. R. Eggers, S. Kabelak. Int. J., Thermophys. 36, 2769 (2015).

7. L. Vasiliev, M. Rabetsky, L. Grakovich, V. Kulikousky, A. Zhuravlyov, M. Kuzmich, 19th International Heat Pipe Conf. and 13th Int. Heat Pipe Symp., Piza, Italy. 22 (2018),

8. L. P. Grakovich, M. I. Rabetskii, L. L. Vasiliev, L. L. Vasiliev Jr., S. P. Bogdanovich, S. S. Pesetskii. Heat Pipe Sci. and Techn. Int. J. 5, 145 (2014). 